\title{
Globalizations Consequences, before and after COVID-19 Attack according to the Theory of Functional Equivalence
}

\author{
Oleg Avilov ${ }^{1, *}$ \\ ${ }^{1}$ South Urals State Medical University. Department of Public Health and Health Care, Chelyabinsk, \\ Russia
}

\begin{abstract}
.
Research background: According to our theory, any need (imbalance) is excess of information, physical and chemical factors that arise in the course of life activities and cannot be eliminated by the body itself without the risk for the health. Satisfying the needs is a search of "channels" for establishing equivalence that is changed number of the mentioned factors for transforming their excess into strictly equivalent functional and structural changes in the organism. Globalization makes it faster. The indicator of that equivalence is established is decreasing of the stress level accompanied by positive emotions in the person.

Purpose of the article: The meaning of economic activity is not the achievement of any economic indicators, but the receipt of positive emotions in producers and consumers. Both production and consumption can be "channels" of establishing equivalence. With the COVID-19 epidemic, the possibilities of establishing equivalence at an optimal pace are significantly reduced.

Methods: The economic and social phenomena observed in society before and after the COVID-19 attack have been analyzed in terms of the basic concepts of functional equivalence theory.

Findings and Value added: Globalization can help to find "channels" for establishing equivalence more quickly through increased opportunities for consumption and production. The limitations of COVID-19 have led to greater imbalances among the populations of many countries without the capacity to reduce them. Constant stress can lead to depression, suicides, antisocial behavior. Ways to prevent these phenomena have been suggested.
\end{abstract}

Keywords: theory of functional equivalence; positive emotions; stress; globalization; COVID-19

JEL Classification: $I 12 ; I 15 ; E 21$

\footnotetext{
${ }^{*}$ Corresponding author: avilveschun@gmail.com
} 


\section{Introduction}

Globalization is the increasing integration of economies and societies around the world. The world, thanks to globalization, becomes more interconnected as a result of the exchange of goods, products, information, knowledge and cultural values. Judging by the fact that serious attempts to implement the ideas of globalization began in the 19th century, globalization provides significant advantages for the producer and consumer of goods and services. At the same time, the UN documents reflect the difficulties that humanity faces in the process of globalization. This process leads to the fact that the ideas of de-globalization are beginning to develop [1]. There is a complex relationship between the processes of globalization and the indicator of development. All the drivers of globalization - financial cooperation, trade, investment, scientific and technological progress and migration - have their socio-economic and environmental impacts and influence policy formulation and implementation at the national, regional and global levels. Managing globalization for the benefit of all remains a major challenge. Economic liberalization has freed up global market forces that have a significant impact on the degree of flexibility countries have in shaping national policies. At the same time, international obligations bind countries to certain international norms and processes. These commitments are extensive, covering economic, social and environmental spheres, and often complex. Countries face many challenges in trying to align international commitments with national priorities, especially when they are all closely related. Developing countries find it most difficult to deal with the negative effects of globalization. Consequently, even in the conditions before the COVID19 pandemic, globalization was accompanied not only by positive effects, but also by consequences for its participants. The pandemic has changed the structure of globalization and led to the emergence of both its real and potential threats and consequences. At the same time, in order to minimize the negative effects of globalization, an understanding of the deep reasons for its appearance and spread in the world community is required. In our opinion, the theory of functional equivalence developed by us is best suited for these purposes.

\section{Methods}

According to our view a need to realize human potential in higher volume is the main reason for globalization. Human potential is inextricably linked with his needs. Effects and consequences of Globalization can be understood with the help of study needs. In accordance with the theory of functional equivalence, we believe that informational, physical and chemical influences on the body should be equivalent to the sum of information, physical and chemical components of life transformed in the body and released from the body [2]. Thus, in our opinion, the need is the development of an imbalance of varying severity caused by an excess of information, physical and chemical factors formed in the process of vital activity, which cannot be removed by the body on its own without the risk of structural disruption. And satisfaction of needs is a search for "channels" for establishing equivalence, that is, an increased or decreased amount of informational, physical and chemical stimuli to eliminate this excess. The end result of satisfying needs is the establishment of equivalence by converting the excess of information, physical and chemical components of life into functional and structural changes in the body. Such, for example, as the excretion or synthesis of certain substances, renewal of the cellular composition, changes in motor and behavioural activity. The process of establishing equivalence can be stepwise. At the same time, the sum of physical, chemical and informational changes in the body after satisfying needs is equivalent to those 
before satisfaction. Only the relationship between the physical, chemical and informational components of the life process is changing. The formation and elimination of imbalances occurs continuously throughout life. From the point of view of our theory, the imbalance already exists at the level of the zygote, and is determined by the initial level of disequilibrium. The higher the level of disequilibrium, the higher, other things being equal, the level of imbalances that must be eliminated in the process of life. It is the initial level of disequilibrium that is, in our opinion, the potential of the organism. In the course of our life, there is a continuous movement from disequilibrium to balance, the final manifestation of which is the death of the organism, or, in other words, the realization of the individual's potential is observed. Thus, within the framework of the theory of functional equivalence that we are developing, by the potential of a living system, we mean the innate capabilities of the organism and its individual systems, determined by the initial disequilibrium to eliminate the manifestations of imbalance that arise in the process of life. The potential cannot but be realized in the process of individual development. The whole point is just how fast it happens, how quickly the body "self-actualizes" thanks to its potential.

To confirm our view, to determine the impact of the COVID-19 pandemic, we studied students' attitudes to each of the five needs represented in the Maslow's pyramid. Students were offered a questionnaire that included several questions. When answering the first question, it was necessary to rank the proposed five needs according to their significance for the student. The second question concerned the definition of students' feelings of emotional tension. The students had to choose one of two possible answers. 1. Subjectively felt emotional tension (stress) is expressed. 2. Subjectively felt emotional tension (stress) is not expressed. The third question allowed us to find out whether the students showed aggression. There were two possible answers to the question. 1. Aggressive thoughts, verbal or physical aggression are expressed. 2. Aggressive thoughts, verbal or physical aggression are not expressed. The study was conducted twice. The first study, which involved 100 students of the South Ural State Medical University (73 girls and 26 boys), took place at the end of March 2020, at the very beginning of the introduction of restrictive measures. The second study, which involved the same students from the same University ( 71 girls and 22 boys), was conducted at the end of May 2020, after almost two months of self-isolation of students and their transition to distance learning. We should add that all students liked possibilities for consumption Globalization gives, and disliked the limitations connected with the COVID-19- epidemic.

\section{Results}

It was found that students we studied had some deviation from Maslow's proposed order in the classic pyramid concerning the hierarchy of needs. It turned out that in the first study, among the needs presented in the Maslow's pyramid, $41 \%$ of students put satisfaction of physiological needs in the first place in importance, $14 \%$ - the need for security, $10 \%$ - the need to occupy a certain place in society, $10 \%$ - the need for love and respect from others, $25 \%$ - the need for self-actualization. 2 months after the introduction of restrictive measures related to the COVID-19 pandemic, the picture of the hierarchy of needs in the Maslow's pyramid has changed somewhat. In the first place, $48.8 \%$ of students (46 people) put physiological needs, $8.6 \%$ of students ( 8 people) - the need for security, $10.7 \%$ of students (10 people) - the need to occupy a certain place in society, $7.5 \%$ - the need for love and respect from others, $24.4 \%$ - the need for self-actualization. We believe that deviation from Maslow's hierarchy of needs can be explained taking into consideration the future profession of the students. According to the data obtained, students ' preferences determined by the Maslow's pyramid remained approximately at the same level after two months of restrictions. At the same time, we were particularly interested in students from 
two groups. The first group consists of students who put the needs of self-actualization first. The second group consists of students who put their physiological needs first. It is for these two groups, which differ fundamentally in their preferred needs, that we analysed the severity of emotional stress and aggressive behaviour before and after the introduction of restrictive measures. In the first study, $44 \%$ of the students in the first group had a pronounced emotional stress (11 people). In the second study, 63.1\% of students (14 people) already felt a pronounced emotional stress. Prior to the restrictions, $24 \%$ of students (6 people) felt some signs of aggressive behaviour. Two months after the restrictions were imposed, $36.3 \%$ of students ( 8 people) felt signs of aggressive behaviour.

Among students of the second group, $43.1 \%$ of students (18 people) felt signs of emotional stress before the restrictions began. After the introduction of restrictions-already $71.7 \%$ of students (32 people). Before the introduction of restrictive measures, $21.9 \%$ of students (10 people) of the second group felt signs of aggressive behaviour. Two months later, $65.2 \%$ of students (32 people) of the second group felt signs of aggressive behaviour. Thus, the restrictions associated with the COVID-19 pandemic had a different impact on students in the two groups. After the introduction of restrictions, students who had the most important need for self-actualization were less likely to experience emotional stress and feel signs of aggressive behaviour than students for whom the main thing was the satisfaction of physiological needs. We can explain this data according to our theory. As we see students of two groups have different ways to use their potential after restrictions.

In the case when the severity of the imbalance is minimal, that is, when the excess of informational, physical and chemical manifestations of the results of functioning is removed at the required speed with the help of stimuli coming from the external and internal environment of the body, the decrease in potential, in our opinion, is minimal. That is, the movement from disequilibrium to balance slows down. Both in case of insufficient and excessive supply of stimuli, an increased level of potential losses is developed, which can lead to both diseases and death of the organism. Since the movement from disequilibrium to equilibrium occurs at an accelerated pace.

An insufficient supply of stimuli with the development of additional imbalances is possible with a sudden change in the usual way of life. This happens, for example, in the case of an illness that confuses a person to bed, if it is necessary to observe quarantine during an epidemic, during imprisonment and in other similar cases including COVID-19 restrictions. More often, there is an excessive flow of stimuli, also accompanied by the appearance of new imbalances. So, with the help of advertising, a person is forced to buy new and new goods and services. Constantly changing fashion creates an imbalance in a person associated with the need to look like this. It is customary in modern society. In turn, the need to follow a certain standard of appearance and behaviour is determined by the desire to eliminate deliberately created imbalances caused by a person's desire to build a career, take a proper place in life, and have a stable and high income. A situation arises in which consuming (or producing) now means that much more will need to be consumed (or produced) in the future.

It should be noted that according to a person's behaviour, it is possible to understand whether he has pronounced imbalances. This behaviour will be determined by such a reaction as emotional stress. From the point of view of the theory of functional systems, emotional stress is formed in all conflict situations in which the subject cannot satisfy his needs [3]. But in accordance with a theory of functional equivalence, the view of the causes of stress may be somewhat corrected. The meaning of a stress reaction, in our opinion, is a response to a situation when the rate of development of an imbalance due to exposure or a sudden absence of exposure to information, physical or chemical factors exceeds the rate of establishment of equivalence. In this case, an attempt is made to urgently generate an equivalent response through different "channels". As a result, there is a change in the 
functioning of almost all body systems. But due to the fact that the body's response is urgent, stress in this phase of its development is accompanied by significant disintegration in the work of functional systems, as well as negative emotions [4]. If the imbalance exists for a long time, then in order to find "channels" for establishing equivalence in the body, chronic emotional stress develops. In our opinion, its manifestations, against the background of negative emotions, can be described as states of frustration, anxiety, and cognitive dissonance. We believe that it is the long-term lack of elimination of imbalances by establishing equivalence that leads to such consequences as burnout syndrome, chronic fatigue syndrome, neuroses, psychosomatic diseases, and, as a result, to a reduction in life expectancy. One of the consequences of chronic emotional stress may be choice of such a "channel" as aggressive behaviour. In our case it is seen that restrictions have led to the increase of emotional tension (stress reaction) in students. But the needs can be satisfied, the meaning of life, as the elimination of highest imbalance, is found. In the case of establishing equivalence in full, a person develops positive emotions and a transition from disorganization to coordination in the work of functional systems occurs [4]. Imbalances associated with human life, including in the economic sphere, can be built in a hierarchical order. The chain of events in this case may look like a transition from an imbalance, expressed insignificantly, through the formation of emotional stress, finding "channels" for establishing equivalence with the simultaneous formation of positive emotions to imbalances of a higher and higher level. We see that students of the first group due to selfactualization chosen as the "channel" of establishing equivalence (realizing their potential at optimum rate) at the highest level have more reasons to get positive emotions. That is why we suppose that restrictions caused by COVID-19 were less important for the first group of students then for the second one. Globalization helps create new and new imbalances (needs) in a person, providing opportunities to eliminate them with the help of new and new "channels" for establishing equivalence. We believe that the students of the second group were more dependent on consumption then the students of the first group. Due to Globalization potential of the second group of the students received practically permanent direction of his spending to get more and more positive emotions consuming new goods and services. It seems that these students were not taught properly to receive positive emotions otherwise. Sudden limitations connected with beginning of COVID-19 Attack have led to the situation when the students of the second group were forced to change the habitual ways to spend their potential. The tendency to aggressive behaviour these students showed most may be considered as a new way to establish equivalence which they found being emotionally stressed.

\section{Discussion}

We believe that the goal of Globalization is to increase the possibility for a person to receive positive emotions. In developed countries, usually, human potential is not spent solely on correcting imbalances caused by the lack of opportunities for simple survival. A person must find additional directions for spending his potential to prevent the consequences of the appearance of new and new imbalances associated with genetically determined disequilibrium. This direction can be productive activity, which leads to the emergence of positive emotions, indicating the establishment of equivalence even in the case when this activity is not accompanied by material reward [5]. If the main imbalance in a person is associated with a shortage of financial resources, he will strive to ensure that the production of goods or services leads to their sale with the subsequent receipt of funds. In this case, the first stage of establishing equivalence will lead to positive emotions in the provision of finished products or services on the market. And the second stage - with the successful sale of what has been produced. If a person is financially wealthy, then the 
production of goods and services, or financial speculation, he needs to get as much money as possible. This process helps to correct the imbalance caused by the feeling of not being safe enough, followed by the formation of positive emotions. If a person's potential is high, the ways of its realization are not fully determined, and financial well-being, in comparison with others, is achieved and maintained, a lack of a sense of security inevitably leads to a desire for power. The possession of power is the "channel" for establishing equivalence, helping to feel secure and to feel positive emotions every time power is exercised. Another procedure for eliminating the feeling of insufficient security in persons with a high level of potential is also possible. The first "channel" for establishing equivalence and eliminating the imbalance can be gaining power, and the second - increasing financial opportunities. But there is one more direction for using human potential, which can be combined with the directions indicated above. At the same time, initially a person receives positive emotions from the money he earned. Further, with the help of money, the imbalances associated with a real or advertising-imposed need to purchase goods and services are eliminated. Almost any purchase leads to the development of positive emotions. The better the advertising works, the more purchases occur. The more purchases, the more often positive emotions and feelings of joy arise. This, in our opinion, is the meaning of economic activity. It should be added that positive emotions, optimism contribute to effective work [6].

In the period leading up to the outbreak of the COVID-19 pandemic, globalization allowed manufacturers to sell their products around the world at minimal cost. Financial speculation has received new development opportunities. There are more reasons for positive emotions. Consumers of goods and services began to show more positive emotions. It is easier and faster to eliminate imbalances caused by the desire to buy something in the context of globalization. Information, including information obtained through the Internet, about how well and qualitatively the consumption process goes in developed countries, stimulates migration. Migrants hope to cope with their imbalances as successfully as inhabitants do in the countries where they move, thinking about the development of the same positive emotions that they see through advertising. In addition, the expansion of production with the implementation of the idea of globalization gave migrants additional employment opportunities [7] and the joyful expectation of higher incomes than in their own country.

Consequently, the following can be called the consequences of globalization.

1. Increase in production and consumption with a risk of complete exhaustion of the Earth.

At the same time, the imbalance associated with the remorse of the manufacturer due to the depletion of natural resources is clearly less than the imbalance caused by the desire to expand production. An increase in output, especially if there is a demand for it, can cause significant positive emotions, both among managers and members of any work collective. An increased supply of both well-known and new in-demand services has similar implications.

2. Formation of a significant part of the population in different countries dependent on positive emotions received due to the constant growth of consumption [8]. This is also facilitated by the speed of correction of imbalances arising from the admitted need to purchase fashionable goods or services.

3. Migration of the population to those countries where it is easier and faster to eliminate the imbalances caused by the lack of funds due to the demand for labour with an increase in the production of goods and services. There is the emergence of an opportunity to consume and receive positive emotions in the same way as the native inhabitants of the host country. At the same time, the imbalance associated with the inferiority complex, which is often observed among migrants, is eliminated, or almost eliminated. At the same time we can see the development of additional stress among migrants due to the need to adapt to the laws and rules of conduct in the host country. 
There is also development of additional stress among the indigenous people of the country where migrants are staying due to the legally supported requirement to tolerate representatives of a different culture. There appears the increased risk of finding such a "channel" for establishing equivalence as mutual aggressive actions of migrants and indigenous people.

4. Cross-border channels for the spread of disease-causing agents or products, including infectious diseases, have grown in speed and size. So the worldwide attack of COVID19 is the consequence of globalization.

The COVID-19 pandemic has made its own adjustments to the globalization process [9]. The goods and services proposed by a number of manufacturers were not in demand due to the introduction of quarantine measures associated with the epidemic. As a result, large segments of the population in various countries either lost their jobs or found themselves in a situation with a significant decrease in income [10]. There appeared a problem of the development of pronounced emotional stress due to a violation of the usual way of life and a change in the structure of consumption, especially in emotionally unstable people [11]. Both producers and consumers of goods and services began the process of seeking new "channels" for establishing equivalence. A number of large companies absorbed smaller enterprises, ensuring their continued existence during the crisis. A number of manufacturers of goods and services have managed to redesign and maintain their relevance in the market. At the same time, the need for the services of migrants dropped sharply [12]. Chronic emotional stress, if the "channels" for establishing equivalence cannot be found for a long time, can lead to significant health problems in the population of most countries and to a reduction in life expectancy [13]. In addition, in modern conditions, the risk of people with a low level of education and culture finding such a "channel" for establishing equivalence as aggressive behaviour, fraught with mass riots, pogroms and even wars, increases.

Thus, after the start of the COVID-19 pandemic, new ones were added to the old consequences of Globalization. The world community must take urgent measures to minimize these consequences in order to prevent threats to the loss of life and health in a significant part of humanity.

\section{Conclusion}

From the point of view of the theory of functional equivalence, the meaning of economic activity is not to achieve any economic indicators, but to obtain positive emotions from both producers and consumers of goods and services. An imbalance (need) formed in a person, both in the course of the natural process of life, and consciously or unconsciously arising from advertising of goods and services, leads to emotional stress and negative emotions. Stress is designed to ensure the finding of "channels" for establishing equivalence at different levels of the organization of a living system. Both production and consumption of goods and services can be a "channel" for establishing equivalence. The rate of establishment of equivalence is individual and is determined by the person's potential. And the degree of development of imbalances, and the potential, and the rate of formation of equivalence can be determined at the individual and group levels. An indicator that the equivalence has been established is a decrease in the level of stress and the development of positive emotions in a person. According to the preliminary study we have carried out, the higher is the level of establishing the equivalence, the more is the possibility to get positive emotions, the less is the risk to get stressed and become aggressive. The consequences of globalization can be called an increase in the possibilities of quickly obtaining a positive emotional state in the process of production and consumption of goods and services. There is a risk of dependence on positive emotions. This dependence, in 
particular, manifests itself in the desire to consume more and more. The COVID-19 pandemic is a consequence of globalization itself, and has led to a change in the conditions of production and consumption. Chronic emotional stress, accompanied by negative emotions, began to be observed in a significant part of the economically active population. The search for new "channels" for establishing equivalence can lead, on the one hand, to the manifestation of aggressive, antisocial behaviour. On the other hand, if the "channels" are not found for a long time, a person may fall into depression, get psychosomatic pathology, become addicted to alcohol and drugs, or even commit suicide. In this regard, in modern conditions, urgent measures are required to protect the population not only from COVID-19, but also from the psychological and social consequences of the pandemic. With the help of education, a person needs to facilitate the search for adequate "channels" for establishing equivalence. It makes sense to correct consumer behaviour, conduct trainings to develop skills for obtaining positive emotions not only through consumption. Of course, changing human behaviour is accompanied by significant difficulties [14], but the existing positive experience [15] can be taken into account and continued.

\section{References}

1. Witt, M. A. (2019). De-globalization: Theories, predictions, and opportunities for international business research. The journal of international business studies, 50, 1053 1077.

2. Avilov, O. V. (2019). Formation of life meaning and health at the foundation of functional eqnivalluce theory. The European Journal of Natural history, 3, 72-74.

3. Sudakov, K. V. (1993). Brain neuronal mechanisms of motivation and reinforcement: system organization of behavior. Integrative Physiology and Behavioral Sciences, 28(4), 396-407.

4. Sudakov, K. V., Yumatov, E. A., Tarakanov, O. P. (1996). The integral criterion of emotional stress. The journal of Stress Management, 1, 37-46.

5. Donven, R., Remmerswaal, M., Zoutenbier, R. (2019). Do Altruistic Mental health Care Providers have Better Treatment Outcomes? The journal of human Resources, 54(2), 310-341.

6. Bogler, R., Somech, A. (2019). Psychological Capital, Team Resources and Organizational Citizenship Behavior. The journal of Psychology, 153(8), 784-802.

7. Tharenou, P., Kulik, C. T. (2020). Skilled Migrants Employed in Developed, Mature Economics: From Newcomers to Organizational insiders. The journal of Management, 46(6), 1156-1181.

8. Reith, G. (2004). Consumption and its discontents: addiction, identity and the problem of freedom. The British journal of Sociology, 55(2), 283-300.

9. Caligiuri, P., De Cieri, H., Minbaeva, D., Verbeke, A., Zimmermann, A. (2020). International HRM insights for navigating the COVID-19 pandemic: implications for future research and practice. The journal of international Business Studies, 51(5), 697713.

10. Bapuji, H., Patel, C., Erstug, G. (2020). Corona Crisis and inequality: why Management Research Needs a Societal Turn. The journal of Management, 46(7), 1205-1222.

11. Jacuta, P. (2019). Personality Trait interactions in Risk for and protection against Social Anxiety Symptoms. The journal of Psychology, 153(6), 599-614. 
12. Aragona, M., Barbato, A., Cavani, A., Gostanzo, G., Mirisoba, C. (2020). Negative impacts of COVID - 19 lockdown on mental health service access and follow-up adherence for immigrants and individuals in socio-economic difficulties. Public Health, 186, 52-56.

13. Selye, H. (1952). The story of the Adaptation Syndrome. Montreal: Acta inc. Medical. Publ.

14. Kelly, M. P., Barker, M. (2016). Why is changing health-related behavior so difficult? Public Health, 136, 109-116.

15. Avilov, O. V. (2020). Psychology of the safe consumption at the foundation of functional equivalence theory. In D. Tsiring, V. Beker \& M. Przygoda (Eds), Economic and Social Development: Proceedings of the $50^{\text {th }}$ international Conference (pp. 359364). Chelyabinsk: Online Edition. 